\title{
CLUSTER FORMATION BY FAST HEAVY ION IMPACT ON METAL ACETATES
}

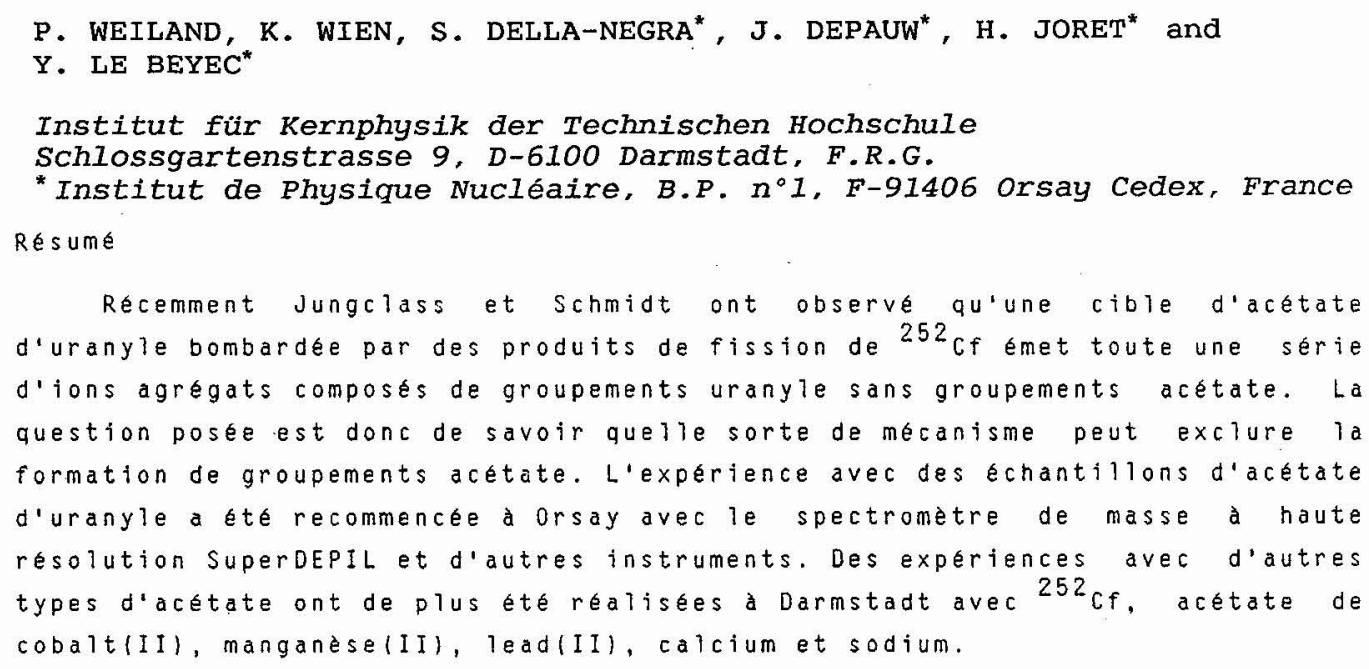

\section{Introduction}

Recently Jungclass and Schmidt observed that solid uranyl acetate eject, under ${ }^{252} \mathrm{Cf}$ fission fragment bombardment, a pronounced series of cluster ion composites of uranyl groups, but not containing acetate groups. So far, it is an open question as to what kind of mechanism excludes the acetate groups from the cluster formation process [1].

The experiment with uranyl acetate was repeated in Orsay using the high resolution Super Depil spectrometer as well as other instruments. In addition, in Darmstadt other acetates were investigated with ${ }^{252} \mathrm{Cf}-$ PDMS as the acetates of cobalt(II), manganese( $\Pi)$, lead(II), calcium and sodium.

\section{Experimental method}

For the measurements in Darmstadt a time of flight mass-spectrometer with an accelaration path of $0.3 \mathrm{~cm}$ and a drift path of $64 \mathrm{~cm}$ was used. The set up of the ${ }^{252} \mathrm{Cf}-\mathrm{PDMS}$-spectrometer is shown in figure 1. One of the two ${ }^{252} \mathrm{Cf}$-fission fragments which are ejected in opposite directions produces the start signal, the other one hits the target from the back and desorbs the secondary ions. The desorbed secondary ions were

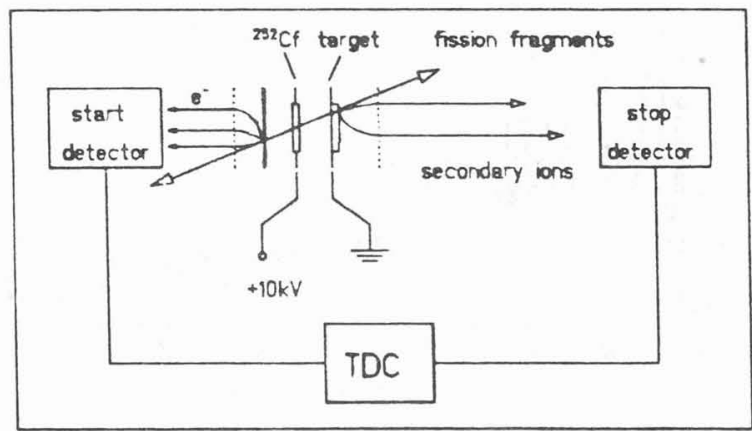

Figure 1: Principle set up of the ${ }^{252}$ Cf.PDMS spectrometer 
accelerated by $10 \mathrm{kV}$. A mass resolution of $\mathrm{m} / \Delta \mathrm{m} \simeq 900 \mathrm{can}$ be obtained with the apparatus. The used TDC is able to count 256 stop signals correlated to one start signal. The marimum resolution was about $0.5 \mathrm{~ns}$ and the dead time of the TDC about $30 \mathrm{~ns}$. The samples were prepared in two different ways - by means of drying and electrospraying.

Drying means that an aqueous solution of the compound was dried on a blank aluminized polyesterfoil. The thickness of the foil was $350 \mu \mathrm{g} / \mathrm{cm}^{2}$. The typical concentration of the solution was in the order of $10 \mathrm{mg} / \mathrm{ml} \mathrm{H}_{2} \mathrm{O}$. One of the problems of the drying method is, that the foil must be equally covered by the deposited compounds. If there are uncovered areas, cluster series of aluminium oxide sppear in the TOF spectrum. To avoid this problem targets were prepared by the electrospray technique, with the compounds were dissolved in methanol. The solution was of the same concentration as in the aqueous one.

\section{TOF.Mass Spectra}

The experiment with uranyl acetate was repeated in Orsay. The mass spectra of the positive and negative ions are shown in figure 2. Cluster series up to $n=50$ were observed in the positive spectrum. In the negative spectrum cluster series up to $n=35$ are found. The cluster ions were composites of uranyl groups. Contributions from acetate groups were weak in negative cluster series and neglegible in positive clusters.
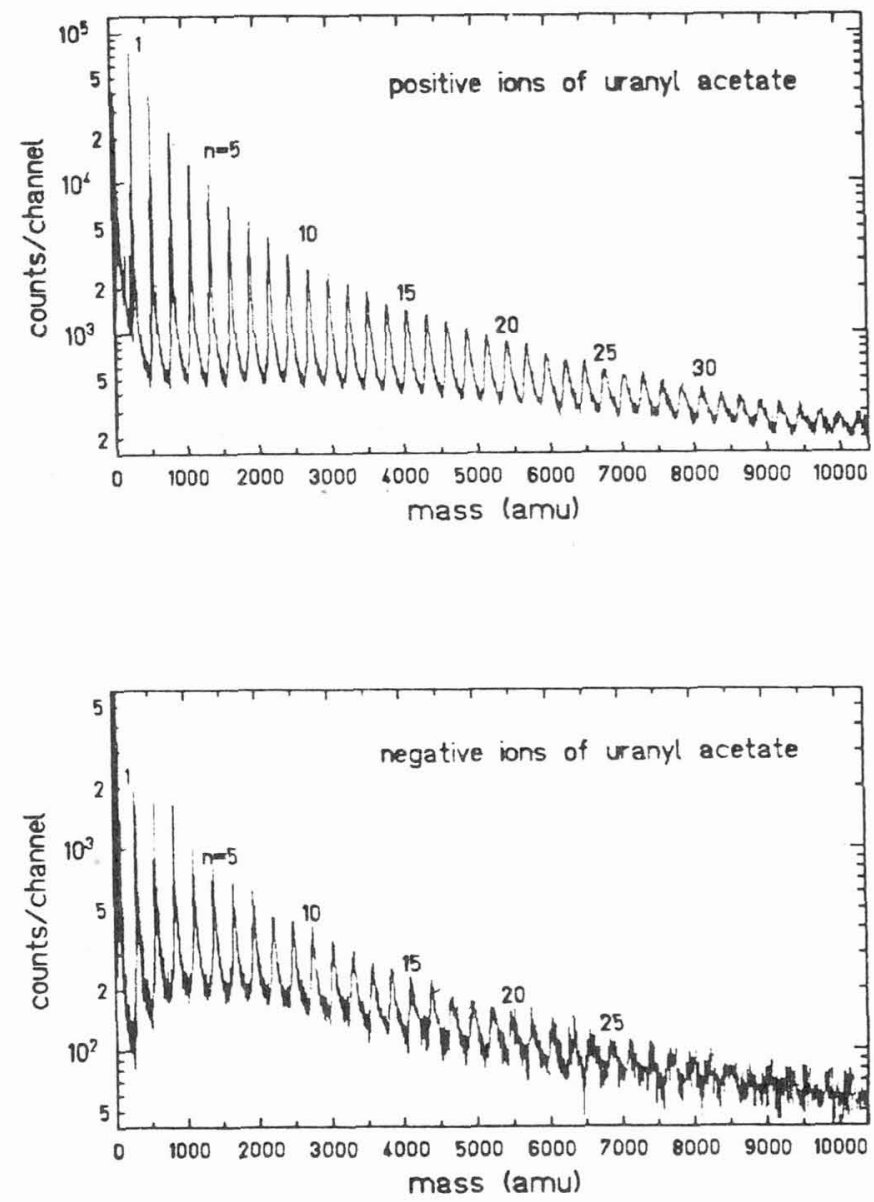

Figure 2: Positive and negative ion spectrum of uranyl acetate 
A comparison of the two apectra shows that the intensity of the positive cluster groups is higher than of the negative ones. The intensity of the cluster lines decreases with increasing $\mathbf{n}$. The following cluster configurations were observed:

$$
\begin{array}{lll}
\text { positive clusters : } & \begin{array}{l}
\left(\mathrm{UO}_{2}\right)_{\mathrm{n}}^{+} \\
\left(\mathrm{UO}_{2}\right)_{\mathrm{n}} \mathrm{U}^{+}
\end{array} & \begin{array}{l}
\left(\mathrm{UO}_{2}\right)_{\mathrm{n}} \mathrm{O}_{\mathrm{m}}^{+} \\
\left(\mathrm{UO}_{2}\right)_{\mathrm{n}} \mathrm{UO}^{+}
\end{array} \\
\text {negative clusters : } & {[\mathrm{m}=1-4]} \\
\left(\mathrm{UO}_{2}\right)_{\mathrm{n}}^{-} & \left(\mathrm{UO}_{2}\right)_{\mathrm{n}} \mathrm{O}_{\mathrm{m}}^{-}
\end{array}[\mathrm{m}=1-4]
$$

There were also some very weak series with acetate groups (figure 3 ):

$$
\begin{array}{ll}
\left(\mathrm{UO}_{2}\right)_{\mathrm{n}}\left(\mathrm{CH}_{3} \mathrm{CO}_{2}\right)^{+} & {[\mathrm{n} \leq 2]} \\
\left(\mathrm{UO}_{2}\right)_{\mathrm{n}} \mathrm{UO}\left(\mathrm{CH}_{3} \mathrm{CO}_{2}\right)^{+} & {[\mathrm{n} \leq 6]} \\
\left(\mathrm{UO}_{2}\right)_{\mathrm{n}}\left(\mathrm{CH}_{3} \mathrm{CO}_{2}\right)^{-} & {[\mathrm{n} \leq 4]} \\
\left(\mathrm{UO}_{2}\right)_{\mathrm{n}} \mathrm{O}\left(\mathrm{CH}_{3} \mathrm{CO}_{2}\right)^{-} & {[\mathrm{n} \leq 4]}
\end{array}
$$

Observed lines:

$$
\begin{aligned}
& \left(\mathrm{UO}_{2}\right) \mathrm{UO}\left(\mathrm{CH}_{3} \mathrm{CO}_{2}\right)^{-} \\
& \mathrm{U}\left(\mathrm{CH}_{3} \mathrm{CO}_{2}\right)^{-} \\
& \mathrm{UO}\left(\mathrm{CH}_{3} \mathrm{CO}_{2}\right)^{-}
\end{aligned}
$$
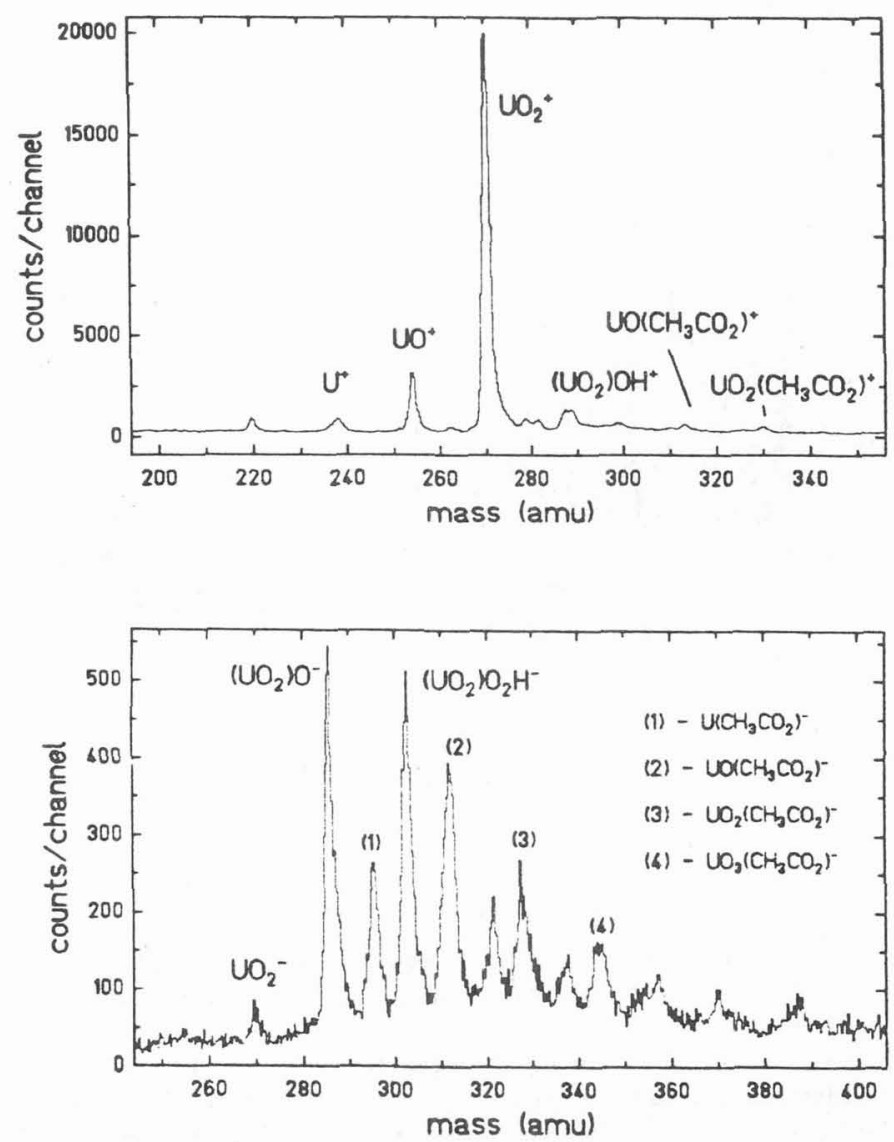

Figure 3: First positive and negative cluster group of uranyl acetate 
One typical spectrum of the other metal acetates is shown in figure 4. The strongest observed cluster series for the positive jons is in all cases $(\mathrm{MO})_{n} \mathrm{H}^{+}$followed by $(\mathrm{MO})_{n} \mathrm{M}^{+}[\mathrm{M}=\mathrm{Pb}$, Co, $\mathrm{Mn}$ and Ca]. Also $(\mathrm{MO})_{n} \mathrm{O}_{m}^{+}$and $(\mathrm{MO})_{n} \mathrm{O}_{m}[\mathrm{~m} \leq 4]$ is found. In the negative mass spectra series of $\left(\mathrm{MO}_{n} \mathrm{OH}^{-}\right.$appear with very strong intensities. The cluster lines of these series can also deprotonate. One weak series was (MO) $)_{n}^{-}$.
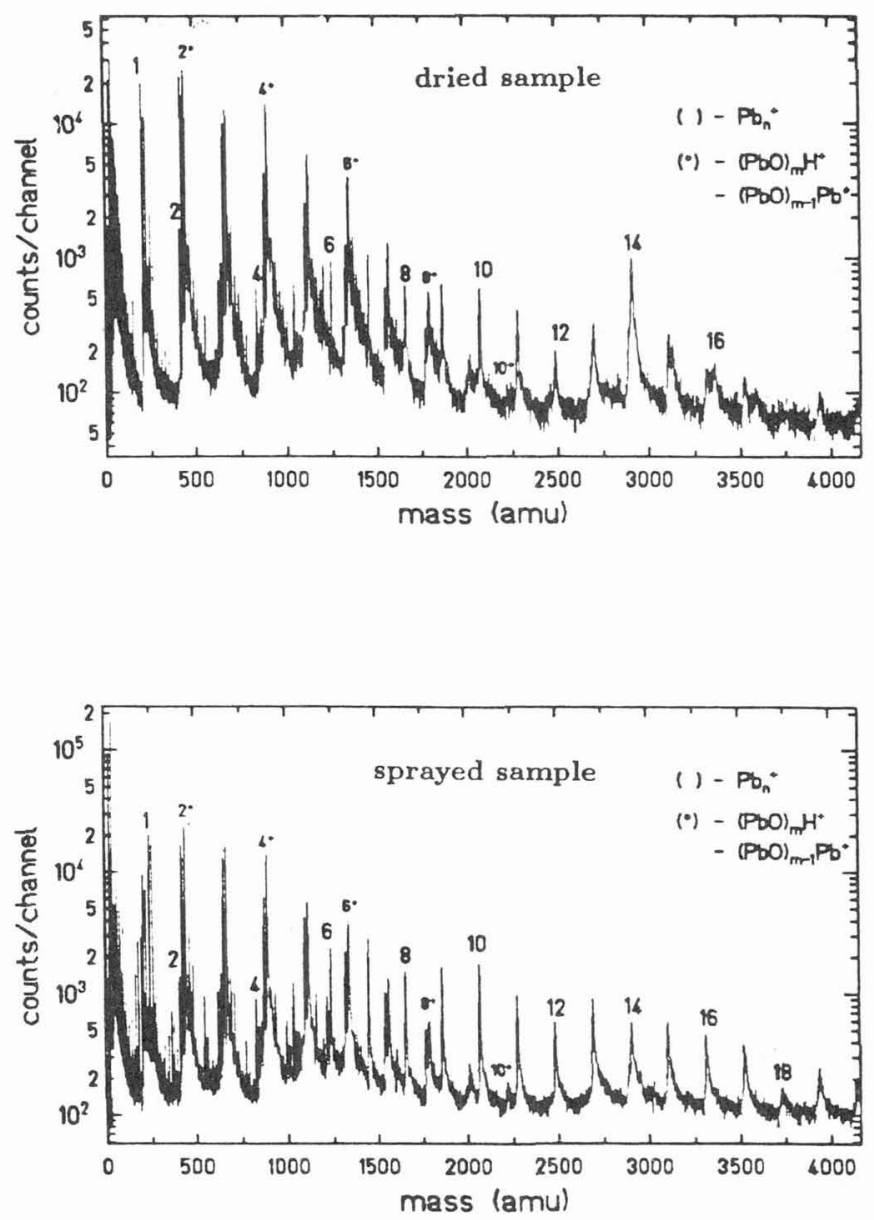

Figure 4: Positive ions of lead(II) acetaite of a dried and a sprayed sample

Pure metal clusters $\mathrm{M}_{n}^{+}$were only observed with lead acetate up to cluster numbers of about 25 . The other coinpounds formed series of minor length. The investigation of the lead acetate series was complicated by the natural isotopic distribution. A comparison of the two target preparation methods shows that the number of observed cluster groups is higher for the sprayed target (figure 4). The time period of the measurements was the same in both cases, the intensities of the first cluster groups were of the same order of magnitude. The marked cluster groups consists of $(\mathrm{PbO})_{n} \mathrm{H}^{+}$and $(\mathrm{PbO})_{n-1} \mathrm{~Pb}^{+}$. Their intensity has a maximum at $n=2$. The yield of the pure metal clusters $P b_{n}^{+}$shows relative maxima at $n=7, n=10$ and $n=13$ (figure 4). In the dried spectrum there is also a relative maximum of the intensity at $n=14$. For this no explanation could be given. 


\section{Results}

We obtained the following results:

1. With exception of sodium acetate all samples emitted series of cluster ions - in most cases up to high numbers of constituents $(n=10-50)$.

2. The basic cluster constituents were the metal oxides. Pure metal clusters $\mathbf{M}_{n}^{+}$formed series of minor length.

3. If the acetate group was involved in cluster formation, the corresponding yields were much smaller than that of the axide cluster.

\section{Conclusion}

Two different extreme ways of cluster ion formation could be possible. First it could be a formation of small axide groups via destruction of the matrix and then condensation to clusters in the gas phase. Secondly it could be a formation of clusters as matrix fragments and then evaporation of acetate groups. In the first case a certain number of inelastic collisions are needed between oxide molecules to build up clusters of high numbers. For the sprayed targets clusters of higher masses were observed; perhaps microclusters were preformed by the spraying procedure at the surface.

\section{References}

[1] H. Jungclas and L. Schmidt Proceedings of the Third International Congress on "Ion Formation from Organic Solids "(IFOS IV) Münster, Sept. 1987 